Accepted version:

Boud, D. and Molloy, E. (2013). Rethinking models of feedback for learning: the challenge of

designAssessment and Evaluation in Higher Education, 38, 6, 698-712.DOI:

10.1080/02602938.2012.691462

\title{
RETHINKING MODELS OF FEEDBACK FOR LEARNING: THE CHALLENGE OF DESIGN
}

David Boud, University of Technology, Sydney

Professor of Adult Education

Faculty of Arts and Social Sciences

University of Technology, Sydney

PO Box 123, Broadway, NSW 2007, Australia

Phone: +6129514 3945, Fax: +61 295143933

david.boud@uts.edu.au

Elizabeth Molloy, Monash University

Associate Professor

Director, Postgraduate Health Professional Education

Office of the Deputy Dean (Education)

Faculty of Medicine, Nursing \& Health Sciences

Monash University, Clayton Campus

Victoria 3800, Australia

Phone: +61399024500

elizabeth.molloy@monash.edu

\begin{abstract}
Student feedback is a contentious and confusing issue throughout higher education institutions. This paper develops and analyses two models of feedback: the first is based on the origins of the term in the disciplines of engineering and biology. It positions teachers as the drivers of feedback. The second draws on ideas of sustainable assessment. This positions learners as having a key role in driving learning, and thus generating and soliciting their own feedback. It suggests that the second model equips students beyond the immediate task and does not lead to false expectations that courses cannot deliver. It identifies the importance of curriculum design in creating opportunities for students to develop the capabilities to operate as judges of their own learning.
\end{abstract}


Higher education institutions are being criticized more for inadequacies in the feedback they provide to students than on almost any other aspect of their courses. In the UK the National Student Survey (Higher Education Funding Council for England, 2011) and in Australia the Course Experience Questionnaire (Krause, Hartley, James \& McInnis, 2009) consistently report that graduates are less satisfied with assessment and feedback than other features of their courses. Is it simply a matter of finding better ways of undertaking feedback or is the notion of feedback as it is commonly used the problem? Many recipes for good feedback are advocated, like the feedback sandwich in which negative comments are sandwiched between two pieces of positive message (Molloy 2010) or the common device of having university-wide rules about the turn around time on students' work. But, in themselves, these nostrums are not effective.. They may represent good institutional etiquette, but evidence suggest that one rule does not fit all situations (Shute 2008). Many other factors of learning design need to be considered.

What is remarkable about feedback in the higher education context is that the normal cultural practices in the marking and return of student work across the disciplines have been largely uninfluenced by any ideas, or practices, or research on feedback from outside the education sector. The assessment practices of academics who teach about feedback in their own disciplines, can remain surprisingly little influenced by their disciplinary understanding of the concept, for example, in engineering (or biology), by the idea that for feedback (or homeostasis) to be said to occur there must be some identifiable influence on the system that is the recipient of the feedback.

The aim of this paper is to explore the puzzling phenomenon of student feedback in higher education and to conceptualise what is needed to reposition it as a practice that has a positive and sustained influence on learning. The paper traces assumptions behind marking and feedback practices and locates them in the changing context of assessment over the past 50 years. It explores two possible directions for improvement. The first of these is to return to the original concept of feedback from the applied sciences to ensure that the feedback loop is completed. As Sadler (1989, p. 121) emphasised, without providing strategies for improving learning and without searching for and monitoring how performance information subsequently influences the learner, feedback may simply be viewed as 'dangling data'. Interestingly, the bulk 
of the feedback literature in higher and professional education focuses on the microskills of the teacher in feedback - that is, how to better dangle the data. The second direction is to rethink the unilateral notion of feedback from one in which information is transmitted from the teacher to the student to a bilateral and multilateral one which positions students as active learners seeking to inform their own judgements through resort to information from various others. These two directions share a common view that feedback must be judged not primarily in terms of its inputs or the conventions or rituals that accompany it, but on identifiable impacts on learning. Both directions present challenges not only to what teachers do in assessment interactions (the current focus of much feedback literature and professional development agendas), but particularly to how courses are designed and structured. Feedback is repositioned as a fundamental part of curriculum design, not an episodic mechanism delivered by teachers to learners.

\section{The changing context of assessment and feedback}

Over the past fifty years or so there has been a slow movement in higher education from an emphasis on final examinations as the determinant of performance towards the use of more diverse, and more continuous, forms of assessment (Heywood 2000). In parallel to a partial shift of formal assessment towards demanding earlier products from students, there has been an erosion of marked student work undertaken only for the purposes of learning. For example, arts students used to regularly complete many essays during a term that did not 'count' for final grades. Prompted by student agitations about assessment in the nineteen sixties and seventies, which focused on the stressful nature of examinations and lack of fairness about being judged at a single point of time (Rowntree 1977), there has been a move to make all required work formally assessed.

Since then, and in response to increases in student numbers and reductions in per capita funding, the number of assessed tasks and their regularity have greatly reduced the amount of information provided to students about their work. The shift towards modularized structures has also reduced opportunities for feedback as tasks get squeezed into fewer and fewer weeks (Hounsell 2007). Fewer tasks overall and fewer 
regular tasks mean students get less practice and less systematic knowledge of their performance.

This more recent regime of assessment, may have come at the expense of worthwhile learning opportunities. Time-on-task, the most thoroughly documented contributor to student achievement (Hattie 2009), and information needed to promote learning has been sacrificed for the sake of coverage and certification. The conditions that make feedback possible - close knowledge of the development of students work over time, and multiple opportunities to make comments - have been diminished by the structural shift in summative assessment. More recent increases in class size, overloading of teaching staff and fragmentation of continuity of teachers mere compound a problem that pre-dates these changes.

In recent years there has been a flourishing of scholarly writing about feedback in higher education, prompted in part by the desire to respond to the critique being mounted by student surveys across different countries. Authors such as Hounsell (Hounsell 2007, Hounsell et al 2008), and Nicol (Nicol and Macfarlane-Dick 2006, Nicol 2009) in Scotland, O’Donovan, Price and Rust (Rust et al 2005, Price et al 2007, Price et al 2010) in England, and Carless (Carless 2006, 2009, Carless et al 2011) in Hong Kong have sought to understand the notion of feedback, undertake interventions involving new assessment activities and elicit important features of feedback practice. They have aimed to provide a secure knowledge base for the many institutional discussions occurring about the reform of student feedback. However, in seeking to clarify the concept there has been a tendency to treat feedback as a single notion that must be understood. What the present paper does is to identify that there is more than one idea of feedback struggling for wider acceptance. In order to improve feedback practices, a rather more fundamental rethinking of the place of assessment and feedback within the curriculum is needed. This will enable us to have a more robust view of feedback: one that focuses primarily on the needs of learning rather than the capacities of the teacher. 


\section{Origins of feedback}

Over recent years, the language of feedback has gained greater prominence. It is commonly used to refer to information provided by teachers to students about their work. Before focusing on its use in courses, we should consider from where the concept of feedback has been drawn and what it means in its originating disciplines. Going back may in fact help us step forward in feedback practices.

The notion of corrective feedback was a key idea of the industrial revolution and a necessary part of the development of early steam engines (Bunch and Hellemans 2004). The concept of feedback used then was that an engine, or indeed any mechanical system, could be regulated through monitoring its output and feeding this information back into the system to control it. Similar ideas about feedback were prevalent in biology, with regard to the adaptation of organisms to changing conditions, but none of these were taken up in education until the mid-twentieth century.

Historically, teachers had corrected student work without any theory of feedback being involved. Marking was regarded as a process intrinsic to teaching: students were informed of their progress with the intention that they should apply themselves more diligently to their studies if they did not perform well. Information from the marking process was available from which students could benefit if they so chose. This notion of feedback has a strong behavioural emphasis that focuses on the external provision of information based on observable performance. It attempted to eliminate any internal or self-evaluative function in feedback (Butler and Winne 1995). The rather surprising assumption appearing to be that it was possible to change others without conscious volition on their part.

The second major development in feedback came in parallel with this. Feedback was taken up extensively for human systems and in system science. As early as 1950, Norbert Wiener, who helped create the science of cybernetics - the interdisciplinary study of the structure of regulatory systems - discussed the notion of feedback as follows:

"Feedback is the control of a system by reinserting into the system the results of its performance. If these results are merely used as numerical data for criticism of the 
system and its regulation, we have the simple feedback of the control engineer. If, however, the information which proceeds backwards from the performance is able to change the general method and pattern of the performance, we have a process which may very well be called learning."

It is ironic then, that when the language of feedback was finally adopted in education, despite attempts by Ramaprasad (1983) and others to do otherwise, it became used in a pre-industrial sense to mean information provided to students intended to influence what they do without any necessary mechanism to ensure that the information was utilised. Feedback became synonymous with 'telling', that is the one-way transmission of information from teacher to student, as if students did not need to be involved and make their own judgements about what they should do. The assumption being that, if only students acted on what they were told, they could improve their performance. Such an assumption rested on an even bolder set of assumptions that the information transmitted was sufficient for such change to occur, that it was unambiguous and would be interpreted the same way by the student as was intended by the teacher. The piling up of one assumption upon another has been an act of faith on which generation after generation of teachers has proceeded.

It is apparent that, in addition to these assumptions about the information itself, this use of feedback could not be corrective in the sense that the early engineers intended. That is, without monitoring students' work to determine if the information provided to them had an effect on what they did. Without this completion of the control loop to ascertain actual effects rather than desired intentions, students could not be reliably influenced. The completion of a feedback loop is needed to adjust the actions of teachers to ensure an impact on student learning. Without this information teachers are blind to the consequences of their actions and cannot therefore act effectively to improve the quality of learning.

In referring back to the original principles of feedback and linking this to the now substantial body of empirical research in education, we can identify what constitutes good feedback in higher education. This leads to what we refer to as Feedback Mark 1. Subsequently, we shall consider a development from this that takes into account 
that students are unlike non-human systems in that they are necessarily agents of their learning. This we will refer to as Feedback Mark 2.

\section{Feedback Mark 1.}

\section{What is good feedback practice in an engineering model?}

The essential feature of feedback, following the original engineering approach is that information about current work is provided to learners to influence the quality of subsequent work. If the term feedback is used, rather than simply information, there needs to be a way of detecting that there has been an effect in the direction desired. The cycle of feedback needs to be completed. If there is no discernable effect, then feedback has not occurred. This places the onus on the teacher, or the person otherwise providing information, to do what is needed to have an effect and to notice the effect. When feedback is understood in this way, feed-forward is not a separate notion but a necessary characteristic of feedback.

The logic of the feedback process in Mark 1, leads to a set of practical consequences in teaching and learning. For example, for this basic version of feedback to be applicable, there needs, at the minimum, to be one task which demonstrates what the student is and is not able to do, and a subsequent one in which a change of performance can be shown. It also implies that at least part of the second task permits the student to demonstrate some of the learning outcomes judged in the first. Therefore, there needs to be an overlap of tasks (or at least the outcomes manifested by the task) for feedback to occur. Sets of isolated tasks that address different learning outcomes minimise the possibility of feedback occurring. Tasks would also need to be located so that there is sufficient time between the first and the second for the information going to students to be prepared, received and acted upon.

For particularly important or difficult to attain outcomes, or for less responsive students, more than one cycle of feedback may be needed to reach the desired end. The answer to the question of how much iteration is needed to achieve a detectable outcome in performance is an empirical one. If more cycles are required than can fit within the normal course length, it raises questions about whether the desired learning outcomes have been realistically set. Or, if the student is unable to reach the target 
learning outcomes it also raises the question as to whether the teacher's advice or the selected intervention (hopefully chosen collaboratively) is, in fact, appropriate. Importantly in this model, knowledge of the effects of the performance information is utilized to modify the nature of the information provided to students. That is, a feedback loop for the learning of teachers is established so that they improve the quality of the 'interventions' they make on students' work.

These consequences necessarily flow from the adoption of the key characteristic of engineering feedback: that feedback involves information used, rather than information transmitted. It means that feedback in this model needs to be conceptualised as an explicit part of the design of a course or program, and not misconceived as a routine, and unconceptualised, part of what is done for any assignment or assessment task.

The particular focus of feedback in this model follows from Ramaprasad's definition of feedback: "Feedback is information about the gap between the actual level and the reference level of a system parameter which is used to alter the gap in some way." (1983: 4). 'The information on the gap between the actual level and the reference level is feedback only when it is used to alter the gap (Ramaprasad 1983: 6). Such a view prompted Sadler (1989: 78) to identify three conditions for effective feedback: (1) student knowledge of the standards that need to be applied; (2) having to compare those standards to the students' own work; and (3) the student taking action to close the gap between the two. The second and third conditions both require the student to actively engage with the feedback. Knowing how to do this cannot be taken as a given. Sadler draws attention to the need for students to "be trained in how to interpret feedback, how to make connections between the feedback and the characteristics of the work they produce, and how they can improve their work in the future.' (Sadler 1989: 78). Too often it is assumed that students know what action to take when provided with diagnostic information about their performance.

In order to assist in the implementation of Feedback Mark 1, there is a considerable body of empirical research, reviewed well by Hattie and Timperley (2007) and Shute (2008), that illuminates many features, particularly related to the type and timing of information provided to students. In this model, the learner is not necessarily 
influenced beyond the set of tasks contained in any given course. That is, it doesn't lead to other than a restricted view of learning: meeting the needs of a teacher or other feedback-giver in a given context. Mark 1 feedback still fits within a paradigm of telling, that is information transmitted to students. It only varies from this in that there is a detection mechanism - completing the feedback loop — to ensure that information is received and acted on.

However, whatever might be principled objections to it, this model fails the test of practicability in everyday teaching and learning in higher education. The practical dilemma of higher education is that the amount and type of feedback that can realistically be given is severely limited by resource constraints and, of course, the tradition and expectation of not 'spoon-feeding' students. Even if the engineering feedback model was entirely acceptable educationally, it could not be used other than selectively. Careful thought would need to be given to the situations that need the kinds of forensic interventions into students' learning that this model provides. Should it be reserved for key or threshold conceptions, for basic writing or analytical skills, for particular kinds of problem solving, or what? What would be so important that the scarce resources of a teacher diligently applied to produce well-directed information and monitor effects in students' work is needed? It could rightly be argued that the scope of teachers can be usefully extended by the use of various digital resources (eg. JISC 2010) but careful selection of exactly what is needed for which purpose would still be required.

The solution may not be to add more surrogate teachers, or more energised teachers, but to change the model. Is a model of feedback that requires others to continually generate information to meet the learning needs of a student, the appropriate direction in which to proceed? In the long term, clearly it is not, as students will graduate and the infrastructure of support for learning that this model assumes has to fade and disappear (Boud and Falchikov 2007). It is simply not sustainable. This is where Feedback Mark 2 may be considered.

\section{Feedback Mark 2}

What is good feedback practice in a sustainable model? 
The main limitation of Feedback Mark 1 is the assumptions it makes about the nature of learners. It assumes that they require others to identify and provide the information they need to learn and that learning is driven by how others go about this process. This accords learners a lowly status with little volition, limited agency and dependence on teachers or a teaching system.

As soon as the active role of learners is acknowledged, then conceptions of feedback need to move from the mechanistic to the responsive. That is, the role of learners as constructors of their own understanding needs to be accepted. Feedback then becomes not a control mechanism designed by others to corral the learner, albeit in desirable ways, but a process used by learners to facilitate their own learning. The metaphor of feedback as a steam regulator or electronic device breaks down. How then would a conception of feedback that places learner agency as central, differ from that of Feedback Mark 1?

Hounsell (2007), building on Boud's discussion of sustainable assessment (2000), introduced the notion of sustainable feedback. Sustainability of feedback would 'be a function of its contribution to equip students to learn prospectively, in their lives and careers beyond graduation'. Hounsell's emphasis was on the provision of high-value feedback, transforming the role of students in feedback and enhancing the congruence of guidance and feedback. Through these features, he argued feedback could be repositioned away from having a short-term effect, to one that continued over time. Carless, Salter, Yang and Lam $(2011,2)$ linked this view with the neglect of the student role in feedback. Using a broad definition of feedback from Askew and Lodge $(2000,1)$ that regards as feedback 'all dialogue to support learning in both formal and informal situations' they extended it through an empirical study of the practices of excellent university teachers. They identified four characteristics of sustainable feedback:

1. involving students in dialogues about learning which raise their awareness of quality performance;

2. facilitating feedback processes through which students are stimulated to develop capacities in monitoring and evaluating their own learning;

3. enhancing student capacities for ongoing lifelong learning by supporting student 
development of skills for goal-setting and planning their learning.

4. designing assessment tasks to facilitate student engagement over time in which feedback from varied sources is generated, processed and used to enhance performance on multiple stages of assignments.

These characteristics encompass some of the necessary features of a new view of feedback. By using these and setting them in a framework of capacity-building, with an appropriate curriculum and a conducive learning environment, we can begin to identify the shape of an approach to feedback that not only respects students' agency in their own processes of learning but can develop the dispositions needed for identifying and using feedback beyond formal educational structures. It shifts feedback from a notion of telling followed by identifiable utilization to one of seeking followed by judgement and identifiable utilization.

The framework proposed is premised on students committed to becoming effective practitioners in the domain of their study. Such commitment places them as active learners who seek to do whatever they need to understand what is required of them, what constitutes good work within the context of their study and whether their efforts at producing good work meet the appropriate standards and criteria within the knowledge domain. Learners rarely enter courses prepared for this, so there is a need to help develop their capacity, and disposition, to operate effectively to seek and utilize feedback.

This approach takes a practice view that sees assessment as a key element of the process of developing and informing the learner's judgements for learning beyond the immediate task (Boud 2009). That is, there is an educative purpose of assessment to inform the practice of learners so that not only do they have the capabilities to produce work that meets the standards of others, but also that they can make their own informed judgements about the process of production of that work, drawing upon the full range of resources available to them.

Enacting Mark 2 is built around three key elements of a learning system: the learners and what they bring, the curriculum and what that promotes and the learning milieu and what that affords. By focusing on each of these from the perspective of the learner 
who seeks to improve their practice, the features of a sustainable feedback modelFeedback Mark 2-can be identified.

\section{Learners and what they bring}

Students enter higher education shaped by their prior experiences. They have developed knowledge and learning skills sufficient for entry, but they are not necessarily equipped for an undergraduate program. While it is expected that students who enter higher education will be accomplished learners who take responsibility for their own learning, the experience of those who teach them suggests that this assumption is not as well-founded as they would desire (Kift, Nelson and Clarke 2010). Teachers report that students may be disengaged, not strongly motivated and have expectations not of being an active learner, but of 'being taught'. If these circumstances cannot be changed, the model of Feedback Mark 1 might be all that can be applied.

However, considerable recent work on student engagement in higher education has sought to challenge this perception and arrange for the transition pedagogy of the first year experience to be one that generates high levels of student engagement and the development of the identity of students 'as learners' who are proactive in their dispositions (see, for example, Kift et al 2010). While the emphasis of many engagement initiatives is on gaining students active participation in classes and tasks, this alone is not sufficient to build the capacity of students to benefit from feedback.

Feedback Mark 2 requires the active positioning of learner as elicitors of knowledge for improvement, not just the recipients of inputs from others. Unless students see themselves as agents of their own change, and develop an identity as a productive learner who can drive their own learning, they may neither be receptive to useful information about their work, nor be able to use it.

Probably the most influential account of feedback in higher education is that provided by Nicol and Macfarlane-Dick's (2006) in their seven principles of good feedback. The assumption behind their principles is one that we share: 'that students are already engaged in self-regulation but that some students are better at self-regulation than others; and it is the weaker students that need opportunities to enhance their sense of 
control.' (Nicol 2009, p. 338). Nicol recognizes that 'students are always informally engaged in the self-regulation of learning when they participate in academic tasks' (p.338) and that

'when students receive feedback from teachers they must engage in selfassessment if they are to use that information to improve academic performance: that is, they must decode the feedback message, internalise it and use it to make judgements about and modify their own work.' (p. 339).

He argues that higher education teachers should build on this capacity to seek, interpret and use, rather than focus all their efforts on providing expert feedback.

Developing this evaluative capacity is central to Feedback Mark 2 and, we suggest, at the heart of any higher education curriculum. Both students and teachers need to see feedback as a way of promoting learning through fostering active learners, not as individual acts of information provision and reception. That is, feedback is not viewed as 'telling', but as 'appreciating'. It ends not in 'telling', or even 'reading', but in acting. It is therefore not a process that is done to students, by educators. All stakeholders in teaching and learning need to be explicitly orientated to the purpose of feedback as self-regulating, and to view it as a means to increase capability in making judgements and acting upon them. This starts with the fostering of learner dispositions towards seeking feedback. Given the myths about feedback that already exist in the minds of teachers and students (Adcroft, 2011), this presents a considerable communication challenge.

\section{The curriculum and what it promotes}

The various notions of feedback discussed here go beyond the commonplace idea of 'helpful information to students about their work'. They are complex interventions into courses that cannot be reduced to prescriptions or even self-contained sets of activities. They need to be seen as permeating the curriculum. They point to the much-overlooked need to consider higher education through the lens of curriculum (Barnett and Coate 2005). Grundy sees curriculum as "a social construction ... the form and purposes of that construction will be determined by some fundamental human interests which imply concepts of persons and their world" (1987, p.19). The interest here being in the formation of a learner who acts in the world with others, who can identify appropriate standards and criteria to apply to their work and who 
actively builds their capacity to make judgements within the domain of their studies and in relation to the world in which they will operate. Such a person is not dependent on a drip feed of comments from teachers, but benefits from the ways in which they construct a fruitful and generative learning environment that helps them calibrate their own judgements (Boud and Falchikov 2007).

The sustainable notion of feedback fits well with Barnett and Coate's (2005) view of the curriculum in higher education as deliberately designed to engage students, among others. They write of

'the imaginative design of spaces as such, spaces that are likely to generate new energies among students and inspire them, and so prompt their triple engagement - in knowing, acting and being. (p.3) [their italics]

Barnett and Coate are sceptical of 'curricula rules and templates' and of specifying 'in advance the elements of every programme of study' (2005, p.3). We see the suggestions for feedback here as illustrations of many ways in which the ideas they contain can be manifest, not as the only ways in which they could or should be manifest.

It is only through taking a curriculum perspective, which is broader than a learning view or an assessment view, that feedback can be adequately located. Such a view enables feedback to be repositioned away from its taken-for-granted role as a feature of the ways teachers act towards students, towards being seen as an attribute of the curriculum that locates it as a central feature of student engagement. Feedback becomes therefore a key curriculum space for communicating, for knowing, for judging, for acting. It is not something that teachers do, any more than it is something students do: it is a necessary characteristic of any given curriculum, the effectiveness of which is a key indicator of the effectiveness of the whole course of study.

What, then, are the curriculum features needed for Feedback Mark 2? Table 1 illustrates features that could be found in such an approach: 


\begin{tabular}{|c|c|}
\hline Feature & Examples \\
\hline $\begin{array}{l}\text { Learners orientated to the } \\
\text { purposes of feedback }\end{array}$ & $\begin{array}{l}\text { Explicit learning outcomes relating to developing } \\
\text { judgements and collaboration with peers, clear } \\
\text { expectations that students actively participate in } \\
\text { classes and that information received will lead to } \\
\text { action }\end{array}$ \\
\hline $\begin{array}{l}\text { Learners participate in } \\
\text { activities promoting self- } \\
\text { regulation }\end{array}$ & $\begin{array}{l}\text { Activities to build student engagement and foster } \\
\text { self-regulation through self-testing of understanding, } \\
\text { reflecting on how the gold standard task (reference } \\
\text { point) compares to student execution of task, or } \\
\text { planning what information they need to meet } \\
\text { learning outcomes. }\end{array}$ \\
\hline $\begin{array}{l}\text { Learner disposition for seeking } \\
\text { feedback is developed }\end{array}$ & $\begin{array}{l}\text { Development of feedback seeking skills through } \\
\text { early practice activities including identification of } \\
\text { appropriate criteria, formulating comments on } \\
\text { others' work, practice in telling tutors what kind of } \\
\text { comments are needed on assignments }\end{array}$ \\
\hline $\begin{array}{l}\text { Opportunities provided for } \\
\text { production of work }\end{array}$ & $\begin{array}{l}\text { Opportunities for students to produce work of the } \\
\text { kind that is central to learning outcomes through } \\
\text { multiple tasks well-designed for this purpose, not all } \\
\text { of which might be formally graded }\end{array}$ \\
\hline Calibration mechanisms & $\begin{array}{l}\text { Channels to enable learners to check knowledge } \\
\text { sources, develop understanding, calibrate their } \\
\text { judgement against expert work and peer work, } \\
\text { regular opportunities to judge their own work before } \\
\text { it is marked. }\end{array}$ \\
\hline Incremental challenge of tasks & $\begin{array}{l}\text { Development of sequences of tasks that } \\
\text { progressively and realistically challenge learners, } \\
\text { assessment tasks progressively build capacity to }\end{array}$ \\
\hline
\end{tabular}




\begin{tabular}{|l|l|}
\hline & tackle more complex problems \\
\hline $\begin{array}{l}\text { Nested tasks to allow for 'feed } \\
\text { forward' }\end{array}$ & $\begin{array}{l}\text { Timing and design of tasks to permit input from } \\
\text { others (teachers, peers, practitioners, learning } \\
\text { management systems, as appropriate) and self on } \\
\text { each task, to be utilized to benefit performance on } \\
\text { subsequent tasks }\end{array}$ \\
\hline Learner as 'seeker and & $\begin{array}{l}\text { Opportunities to practice the giving as well as the } \\
\text { receiving of feedback. Orientation of learners to } \\
\text { dimensions of the target performance (they need to } \\
\text { engage with the desired learning outcomes, so they } \\
\text { can make and articulate a comparative judgement). }\end{array}$ \\
\hline
\end{tabular}

Table 1: Curriculum features characteristic of Feedback Mark 2

Of special importance is the practice of students in making judgements about their own work and that of others. From early in the program, students need opportunities to judge their own performance, to see how this appraisal compares with appraisal by others. This can assist them to develop awareness of what they do and do not know or can and cannot do. Without such awareness students cannot plan for further learning. These opportunities may constitute regular activities to assess students' content knowledge or they could, for example, take the form of criterion-referenced processes that learners engage in following written or practical skill performance. In the case of verbal feedback exchanges (for example post-oral presentations), educators can scaffold students self-monitoring capacity through asking questions about the student's own account of the performance. The subsequent provision of educator opinion may then validate or contest the learner's internal evaluation, strengthening knowledge about the relationship between task goal and execution. The challenge for educators is to systematically build these expectations of learner self-analysis into the curriculum. The regularity of self-analysis builds habits, so that self-judgement and 
seeking how this compares to external appraisal becomes second nature, and part of learning practice, rather than an uncomfortable episode of intellectual risk-taking.

While some of these features might also be found in a curriculum model supporting Feedback Mark1, it is the particularities and the assumptions of student agency that place these within Feedback Mark 2. In particular, it is the dialogical nature of these elements (Carless 2007, Bloxham and Campbell 2010) that positions them as contributing to a sustainable approach. For example, while some learning outcomes may of course be specified, others would be negotiated. A systemic approach to the design of courses and tasks is needed for such an approach to be effectively implemented.

\section{Learning milieu and what that affords}

While the curriculum 'as it is designed' may influence learners and what they do, it is the curriculum 'as it is enacted' (Barnett and Coate 2005) that has a direct impact on students. Much of the curriculum as enacted is not what is formally documented in learning outcomes and course descriptors, but occurs in the everyday interactions students have with staff, with each other and the context in which they operate. The translation of the curriculum into the everyday learning milieu is crucial in realising this approach. This milieu is constituted from not only requirements and curriculum specifications, but more importantly from expectations of teaching staff and interactions with others, especially peers. Formal, high-stakes assessment tasks are also a powerful influence on the learning milieu as the significance invested in them by students can override any exhortations by teachers.

Feedback Mark 2 is dependent on a learning environment that fosters continual improvement and creates opportunities for knowledge seeking and application by students. Such an environment is fostered by considerations at all levels from formal assessment tasks and requirements to the configurations of teaching and learning spaces, the gestures of teachers, the questions of learners and teachers and the climate of cooperation between students. These learning environments do not come readymade but need to be constructed not only by individual teachers responsible for courses, but also by staff and students working together to construct suitable milieu. 
The prime characteristic of the necessary learning milieu for this conception of feedback is that it is one in which dialogue flourishes. As Carless et al (2011) have emphasized, students need to engage in dialogue about monitoring their own work, what constitutes appropriate standards of judgement and plan their own learning if they are to discriminate what is quality performance and enact it. Dialogue is also needed to interpret standards and criteria and discern how they are manifest in their own work and that of others. Dialogue here should not be taken literally as face-toface or one-to-one conversations, but as all forms of interactions of different kinds with different actors (teachers, peers, practitioners, consumers, learning systems) with a view to eliciting perceptions and judgements and discerning what is needed for improved action.

A further important dimension in considering the learning milieu is what Carless (2009) has identified as trust. Learners will only act on the basis of trustworthy information. If they believe that comments are capricious or ill considered, or do not take the student as person into account, they will not act on the basis of them. Typically, a relationship of trust is assumed between student and teacher, or at least an assumption that power relations or assumed expertise (warranting status as a good judger of good work) might lead to the teacher's comments being taken seriously. However, with others, a relationship of trust needs to be built. With other students, this can occur as a result of progressive sharing of information recognized by the other to be valid: there may be no default position of assumed trust. The questions to be asked of any 'other' in a feedback relationship are: does the provider have my interests at heart? How can trust be built? There is a role in the establishment of a learning milieu to provide a context in which such relationships can flourish and not be undermined by, for example, students being asked to generate grades for each other which might compromise assumptions of 'peerness' on which trust can be built. Power relations profoundly influence trust and indeed other features of the learning milieu. It cannot be simply designed-in to teaching and learning interactions, it is hard-won and there are limits to what teachers or students can do alone. As studies of trust in the (different) learning context of the workplace suggests, there are often structural and positional constraints (Hughes 2004) that mean that the ideal of reciprocal communication cannot be achieved within some relationships. The summative assessment role of university teachers is perhaps an example of where 
dialogue may be inhibited. Likewise, the perceived high status of the teacher may inhibit students' own self-evaluation of performance. That is, they acquiesce to the teacher's viewpoint and devalue their own judgements. The issues of trust, status, perceived status and power and their impact on student ownership of feedback processes clearly require further empirical study.

It should be noted that Feedback Mark 2 still retains the key idea of Feedback Mark1: in that any knowledge acquired needs to be acted upon in subsequent work for the term feedback to be legitimately used to describe the process. Because such knowledge is actively sought by the leaner it is far be more likely to be utilized than in the engineering model. The challenge for learners is not only to acquire understanding of the appropriate standards and criteria and monitor their performance against these, but also to find new opportunities to put this learning into practice and find ways of judging their own work. Completion of the feedback loop is necessary to ensure that learners are not fooling themselves in the process of self-regulation. This work of calibration will often require the use of others and iterative task engagement.

\section{Implications}

This paper has argued for an extension of the notion of feedback - beyond an episodic, mechanistic practice towards an overarching notion of student selfregulation to frame a curriculum (and that also translates to day to day practices within the curriculum). This conceptual shift is founded upon another premise, that is, about the way that we think about how learners operate within a course. Higher education courses have not traditionally been framed in terms of learners, curriculum and learning milieu, but in terms of disciplinary content and perhaps, more recently, learning outcomes. Such a feedback framework therefore poses many challenges as it involves putting new ideas, such as the practice of learners and developing judgement as central concerns.

We have addressed basic conceptions of feedback that might be used to frame practices in courses. Whilst features of the two models are presented, translation into particular forms will vary greatly according to the context, the learners and the 
particular resource constraints. The models themselves focus on the emphasis of a curriculum and learning milieu, not on implementation. It should not be assumed however that because there is a focus on matters such as student action, or dialogue, Feedback Mark 2 is an ideal, or will be more resource-intensive to implement. Our own view is that this is certainly not the case. Whether it is or not is obviously a function of overall curriculum priorities and which presently ineffective practices one is willing to remove. Certainly a redistribution of effort is involved in the redesign of tasks, their sequencing and the preparation of students to be involved in them, but this can be more than balanced by eliminating commentary on students' work that does not lead to action or that is offered at times when they cannot be reasonably be expected to be taken up.

In summary, rethinking feedback for learning repositions feedback:

1. From an act of teachers to an act of students in which teachers are part (from unilateral to co-constructed; from monologue to dialogue)

2. From the almost exclusive use of teachers to that of many others (from single source to multiple sources)

3. From an act of students as individuals to one that necessarily implicates peers (from individualistic to collectivist)

4. From a collection of isolated acts to a designed sequence of development over time (from unitary items to curriculum)

The insistence of a learning-centred approach does not render the teacher redundant in feedback. But rather, the repositioning demands of the teacher a different set of competencies. Teachers become designers and sustainers of the learning milieu; establishing conditions in which students can operate with agency. The focus of sustainable feedback shifts from the provision of feedback to the design of learning environments, the seeding of generative tasks and the fostering of interactions with and between students and staff. Teachers in the early years of a program become facilitators of shifts in identities as well as creators of attractive learning opportunities and behaviours.

Does this mean that the concept of feedback as commonly used is redundant? In the sense that feedback is an act undertaken principally by teachers for the assumed 
benefit of students, the answer is probably yes. Framing assessment this way can tend to foster dependency and place responsibility too far in the direction of teachers. However, in the sense that feedback processes are needed within the overall learning environment, the answer is no. Teachers need information about student learning if they are to create and sustain productive learning environments that foster selfregulation, and if they are to intervene effectively when the environments they have created do not work as intended. Students still need detailed and timely information about how their work meets the requirement of good work, they still need models and exemplars that represent the standards for which they are striving, and they still need information to enable them to refine and calibrate their own judgements. Ironically, students may need to appreciate Feedback Mark 1 with its strengths and limitations if they are to thrive in a Mark 2 context.

Nevertheless, we suggest that the focus of feedback has to shift. Teachers need better quality information about student learning than they have been getting, and students need to better exercise their skills in eliciting the kinds of information they need. These are still feedback processes, but ones that are mutually constructed and codependent. The measures of success also change in this shift. They move from a prime focus on timely and detailed information, to one in which the focus is on the appropriateness of timing and the nature of information for fostering self-regulation.

(This cannot be determined by simple measures like turn-around time or details of comments. They also require sophisticated measures of the learning environment and not just of student or teacher actions.)

\section{References}

Adcroft, A. (2011). The mythology of feedback, Higher Education Research and Development, 30, 4, 405-419.

Askew, S., and C. Lodge. 2000. Gifts, ping-pong and loops - linking feedback and learning. In Feedback for Learning, S. Askew (Ed), London: Routledge, 1-17.

Barnett, R. \& Coate, K. (2005). Engaging the Curriculum in Higher Education. Maidenhead: SRHE/Open University Press.

Bloxham, S. and Campbell, L. (2010) Generating dialogue in assessment feedback: exploring the use of interactive cover sheets, Assessment \& Evaluation in Higher Education, 35: 3, 291-300 
Boud, D. (2000). Sustainable assessment: rethinking assessment for the learning society. Studies in Continuing Education. 22 (2), 151-167.

Boud, D. (2009). How can practice reshape assessment? In Joughin, G. (Ed.) Assessment, Learning and Judgement in Higher Education. Dordrecht: Springer, 29-44.

Boud, D. and Falchikov, N. (2007). Developing assessment for informing judgement. In Boud, D. \& Falchikov, N. (Eds.) Rethinking Assessment for Higher Education: Learning for the Longer Term. London: Routledge, 181-197.

Bunch, B. and Hellemans, A. (2004). The History of Science and Technology, Boston, Houghton Mifflin.

Butler, D.L. \& Winne, P.H. (1995). Feedback and self-regulated learning: a theoretical synthesis. Review of Educational Research. 65 (3), 245-281.

Carless, D. (2006). Differing perceptions in the feedback process. Studies in Higher Education, 31 (2): 219-33.

Carless, D. (2009). Trust, distrust and their impact on assessment reform, Assessment \& Evaluation in Higher Education, 34, 1, 79-89.

Carless, D., Salter, D., Yang, M and Lam, J. (2011) Developing sustainable feedback practices, Studies in Higher Education, 36, 5, 395-407.

Ende, J. (1983) Feedback in clinical medical education. Journal of American Medical Association 250: $777-781$.

Grundy, S. (1987). Curriculum - Product or Praxis? London: The Falmer Press.

Hattie, J. (2009). Visible Learning: A Synthesis of Over 800 Meta-Analyses Relating to Achievement. London: Routledge.

Hattie J, and Timperley H. (2007). The power of feedback. Review of Educational Research. 77, 81112.

Higher Education Funding Council for England. (2011). The National Student Survey: Findings and Trends. 2006-2010. Bristol: Higher Education Funding Council for England

Hounsell, D. 2007. Towards more sustainable feedback to students. In Rethinking Assessment in Higher Education, ed. D. Boud and N. Falchikov, 101-13. London: Routledge.

Hounsell, D., V. McCune, J. Hounsell, and J. Litjens. (2008). The quality of guidance and feedback to students. Higher Education Research \& Development, 27, no. 1: 55-67.

Hughes, C. (2004). The supervisor's influence on workplace learning, Studies in Continuing Education, $26,2,275-287$.

Ilgen D and Davis A. Bearing bad news: Reactions to negative performance feedback. Applied Psychology: An International Review, 49: 550-565.

JISC. (2010). Effective Assessment in a Digital Age, Bristol: JISC. http://www.jisc.ac.uk/digiassess Kift, S., Nelson, K. and Clarke, J. (2010). Transition pedagogy: A third generation approach to FYE A case study of policy and practice for the higher education sector, The International Journal of the First Year in Higher Education, 1, 1, 1-20. 
Krause, K., Hartley, R. James, R. and C. McInnis, C. (2009). The first year experience in Australian universities: Findings from a decade of national studies. http://www.cshe.unimelb.edu.au/research/experience/docs/FYE_Report_1994_to_2009.pdf

Molloy, E. (2010). The feedforward mechanism: a way forward in clinical learning? Medical Education, 44: 1157-1159.

Nicol, D (2009), Assessment for learner self-regulation: Enhancing achievement in the first year using learning technologies, Assessment and Evaluation in Higher Education, 34(3), 335-352.

Nicol, D., and Macfarlane-Dick, D. (2006). Formative assessment and self-regulated learning: A model and seven principles of good feedback practice. Studies in Higher Education, 31, 2: 199-218.

Price, M, Handley, K., Millar, J and O’Donovan, B. (2010). Feedback: all that effort, but what is the effect? Assessment \& Evaluation in Higher Education, 35, 3, 277-289

Price, M, O'Donovan, B and Rust, C (2007). Putting a social-constructivist assessment process model into practice: building the feedback loop into the assessment process through peer review. Innovations in Education and Teaching International, 44 (2), 143-152.

Ramaprasad, A. (1983) On the definition of feedback, Behavioral Science, 28, 4-13.

Rowntree, D. (1977). Assessing Students: How Shall We Know Them? London, Harper \& Row.

Rust, C, O’Donovan, B. and Price, M. (2005) A social constructivist assessment process model: how the research literature shows us this could be best practice, Assessment \& Evaluation in Higher Education, 30, 3, 231-240.

Sadler, D.R. 1989. Formative assessment and the design of instructional systems. Instructional Science, 18, 2: 119-44.

Shute, V J (2008) Focus on formative feedback, Review of Educational Research, 78, 1: 153-189

Wiener, N. (1950). The Human Use of Human Beings: Cybernetics and Society. Boston, Houghton. 